\title{
APCI Low Energy Collision-Induced Dissociation Fragmentation of Protonated Ortho Silicates: McLafferty or Ion-Neutral Complex Rearrangement?
}

\author{
Donald V. Kenny and Susan V. Olesik \\ Department of Chemistry, The Ohio State University, Columbus, Ohio, USA
}

\begin{abstract}
The fragmentation mechanism of tetraethyl ortho silicate and tetrapropyl ortho silicate was studied to determine if the consecutive alkene losses observed in their MS/MS daughter ion spectra were produced via a McLafferty rearrangement or by ion-neutral rearrangement mechanisms. The experiments were carried out using atmospheric pressure chemical ionization and low energy collision-induced dissociation. Deuterium labeling of the $\gamma$-position provided evidence that the rearrangement mechanism of the successive alkene losses proceeds predominantly via the ion-neutral complex mechanism. Because the energies imparted to the ions in this experiment are of the same order of magnitude as solution phase reactions, this mechanism may shed light on the formation of silica gels (e.g., aerogels) in that similar structures have been proposed as reaction intermediates in the polymerization of $\mathrm{SiO}_{2}$. (J Am Soc Mass Spectrom 1994, 5, 544-552)
\end{abstract}

$\mathrm{T}$ Tetraethyl ortho silicate (TEOS) is used as the precursor in many hydrolysis and polycondensation reactions for the preparation of silica gels. The reaction mechanism of silica gel formation is complex and incompletely determined. Previous studies used mass spectrometry to define possible reaction intermediates $[1,2]$. A better understanding of the solution phase chemistry of TEOS may be gained by studying the gas phase chemistry under atmospheric pressure chemical ionization (APCI) conditions. Parallels can be drawn between the reactions in the gas phase (gas phase solvolysis) and reactions in solution [3-5]. In this study gas phase reactions involving TEOS and tetrapropyl ortho silicate (TPOS) with $\mathrm{H}_{3} \mathrm{O}^{+}$and subsequent low energy collision induced dissociation (CID) reactions were used to study the fragmentation mechanism.

Clarification on whether the ortho silicate fragmentation mechanism is a McLafferty rearrangement or the result of ion-neutral reactions may give insight into the formation of silica gels (e.g., aerogels) because similar structures have been proposed as reaction intermediates in the polymerization of $\mathrm{SiO}_{2}[1,2]$. With the renewed interest in the synthesis of aerogels, it is hoped that by understanding these low energy gas phase ion-molecule reactions further insight into the

Address reprint requests to Dr. Susan Olesik, Department of Chemistry, Ohio State University, 120 West 18 th Avenue, Columbus, Ohio, 43210 . solution phase chemistry of the formation of silica based gels can be gained.

\section{Experimental}

A SCIEX trace atmospheric gas analyzer (TAGA Model $6000 \mathrm{E}$ ) triple quadrupole tandem mass spectrometer system equipped with a corona-discharge, APCI source was used $[6,7]$. With ambient air as the reagent gas, the positive reagent ions are $\mathrm{H}_{3} \mathrm{O}^{+}\left(\mathrm{H}_{2} \mathrm{O}\right)_{n}(\mathrm{n}=0-8)$ where the relative abundance of the various oligomers depends on the partial pressure of $\mathrm{H}_{2} \mathrm{O}$ in the air. The reaction mechanism involved in the formation of these reagent ions has been described by Kebarle and coworkers [8]. A molecule can be ionized under these conditions if it has a gas phase basicity greater than that of water [9].

Table 1 summarizes the instrumental conditions used in this study. Even though the TAGA has only two mass analyzing quadrupoles, grand-daughter spectra can be obtained [7]. Using the interface region as the first collision cell and allowing the first mass analyzing quadrupole to pass the daughter ion of interest, the rf-only quadrupole becomes the second collision cell with the second mass analyzing quadrupole scanning (or selecting) the granddaughters. The TAGA 6000E is different from the newer API' III and API $\mathrm{III}^{+}$models in that the $6000 \mathrm{E}$ is equipped with a "cluster buster" lens after the orifice and the R0 quadrupoles are wire rods allowing for 
Table 1. Summary of instrumental parameters

\begin{tabular}{ll}
\hline Discharge current & $3 \mu \mathrm{A}$ \\
Orifice potential & $40 \mathrm{~V}$ \\
Rod offset $\mathrm{Q1}$ & $27 \mathrm{~V}$ \\
Rod offset $\mathrm{Q} 2 / \mathrm{O3}$ & $10 \mathrm{~V}$ \\
Collision energy, $\mathrm{E}_{\mathrm{lab}},($ OR-R2) & $30 \mathrm{~V}$ \\
Collision gas thickness (argon', molecules $/ \mathrm{cm}^{2}$ & \\
$\quad \begin{array}{l}\text { Single Collision Regime } \\
\text { Multiple Collision Regime }\end{array}$ & $0.5 \times 10^{14}$ \\
lonization Source Pressure & $3.55 \times 10^{14}$ \\
Vacuum System Pressure (with collision & Atmospheric \\
$\quad$ gas off), Torr & $2 \times 10^{-6}$ \\
\hline
\end{tabular}

${ }^{8}$ OR - Orifice potential; R2 - Rod offset $Q 2$.

efficient gas removal. The TAGA 6000E's collision cell (Q2) is an open configuration with wire rods. Previous work in our laboratory comparing the spectra generated by the $6000 \mathrm{E}$ and API III showed that the presence of the "cluster buster" produced ions with lower internal energy when all other ion source conditions are held constant.

Samples were introduced into the TAGA air stream by placing an open vial of the compound of interest at the inlet and having the instrument "sniff" the headspace of the vial. The $\mathrm{H}_{3} \mathrm{O}^{+}$reagent gas was generated from the normal humidity found in the laboratory air. Tetraethyl ortho silicate $(99+\%$ purity) and tetrapropyl ortho silicate (98\% purity) were purchased from Aldrich Chemical Co. (Milwaukee, WI), and used without further purification. A deuterated TEOS, $\left(\mathrm{CD}_{3} \mathrm{CH}_{2} \mathrm{O}\right)_{4} \mathrm{Si}$ and deuterated TPOS, $\left(\mathrm{CH}_{3} \mathrm{CD}_{2}\right.$ $\left.\mathrm{CH}_{2} \mathrm{O}\right)_{4} \mathrm{Si}$, were synthesized following the procedure outlined by Dearing and Reid [10]. The appropriate deuterated alcohol was reacted with silicon tetrachloride under dry nitrogen to form the deuterated tetraalkyl ortho silicate. The deuterated ethanol, $\left(\mathrm{CD}_{3} \mathrm{CH}_{2} \mathrm{OH}\right.$ ), (98\% purity), was purchased from MSD Isotopes, (Montreal, Canada), the deuterated propanol, $\left(\mathrm{CH}_{3} \mathrm{CD}_{2} \mathrm{CH}_{2} \mathrm{OH}\right)$, (98\% purity), was purchased from Icon Services Inc. (Summit, NJ). Hydrogen and deuterium NMR spectra of the synthesized deuterated compounds showed that the deuterium labels were in the correct position in the final products and no mixing of the hydrogens and deuteriums occurred during the synthesis.

\section{Results and Discussion}

Figures 1 and 2 are the MS/MS daughter ion spectra of the $[\mathrm{M}+\mathrm{H}]^{+}$ions for TEOS and TPOS. Tables 2 and 3 give the proposed structures for the daughter ions in the spectra. The daughter ions with $m / z 181$, 153,125 , and 97 in TEOS are the result of successive ethylene losses. The daughter ions of $m / z$ 163, 135, $119,107,91,79,63$, and 29 in TEOS are the result of direct cleavages from the parent ion or from direct cleavage from a daughter ion of higher mass-to-charge ratio than itself. The daughter ions resulting from the

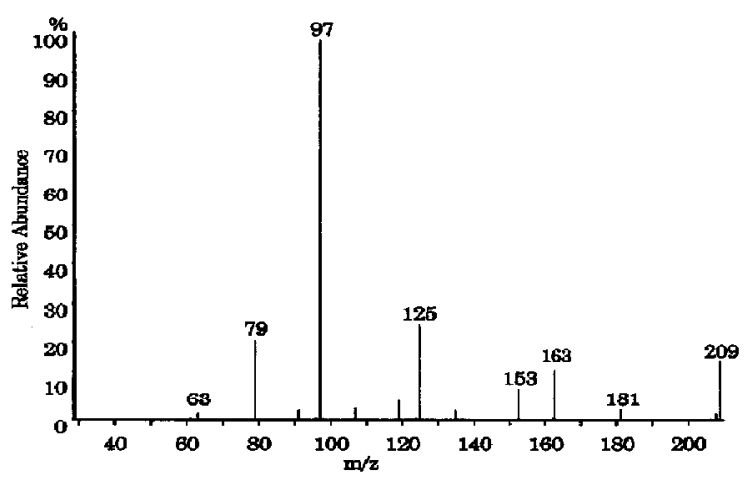

Figure 1. APCI tandem mass daughter ion spectrum of $[\mathrm{M}+\mathrm{H}]^{+}, m, 2209$, from tetraethyl ortho silicate.

successive loss of ethylene appear to be the same species observed in the condensed phase reactions producing $\mathrm{SiO}_{2}$ under acidic conditions as reported by Campostrini et al. [1]. (Assuming that these species are the same, the determination of the fragmentation mechanism may lend insight into the mechanism in the formation of silica gels.)

In the TPOS spectrum the daughter ions with $\mathrm{m} / \mathrm{z}$ $223,181,139$, and 97 are the result of successive propylene losses. The daughter ion $m / z 79$ in the TPOS spectrum is the result of a direct cleavage of a hydroxyl moiety from $m / z 97$ and $m / z 43$ is a protonated propylene group.

Upon first interpretation of the spectra it appears that these molecules undergo successive McLafferty rearrangements which produce ions with $m / z 181$, 153,125 , and 97 for TEOS and ions with $m / z 223,181$, 139, and 97 for TPOS. Schemes I and II illustrate McLafferty rearrangements that correspond to the observed rearrangement ions for TEOS and TPOS. To confirm the existence of a true McLafferty rearrangement mechanism, Zollinger and Seibl [11] suggested that the following criteria must be met:

1. The macroscopic result must conform with a $\gamma$ hydrogen rearrangement in a six-member cyclic

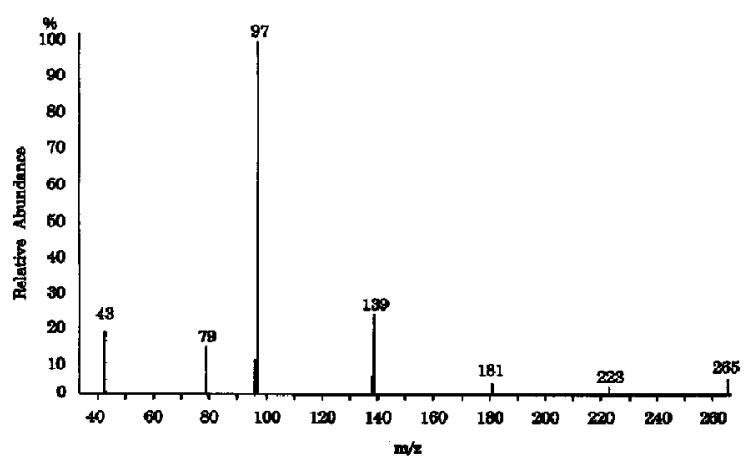

Figure 2. APCl tandem mass daughter ion spectrum of $[\mathrm{M}+\mathrm{H}]^{+}, m / 2265$, from tetrapropyl ortho silicate. 
Table 2. Proposed structures of daughter ions from TEOS [M $+\mathrm{H}]^{+}$

\begin{tabular}{ll}
\hline $\mathrm{m} / \mathrm{z}$ & \multicolumn{1}{c}{ Structure } \\
\hline \hline 209 & $\mathrm{Si}\left(\mathrm{OCH}_{2} \mathrm{CH}_{3}\right)_{4} \mathrm{H}^{+}$ \\
181 & $\left(\mathrm{CH}_{3} \mathrm{CH}_{2} \mathrm{O}\right)_{3} \mathrm{SiOH} \mathrm{H}^{+}$ \\
163 & $\left(\mathrm{CH}_{3} \mathrm{CH}_{2} \mathrm{O}\right)_{3} \mathrm{Si}^{+}$ \\
153 & $\left(\mathrm{CH}_{3} \mathrm{CH}_{2} \mathrm{O}\right)_{2} \mathrm{Si}(\mathrm{OH})_{2} \mathrm{H}^{+}$ \\
135 & $\left(\mathrm{CH}_{3} \mathrm{CH}_{2} \mathrm{O}\right)_{2} \mathrm{Si}(\mathrm{OH})^{+}$ \\
125 & $\left(\mathrm{CH}_{3} \mathrm{CH}_{2} \mathrm{O}\right) \mathrm{Si}(\mathrm{OH})_{3} \mathrm{H}^{+}$ \\
119 & $\left(\mathrm{CH}_{3} \mathrm{CH}_{2} \mathrm{O}\right)_{2} \mathrm{Si} \mathrm{H}^{+}$ \\
107 & $\left(\mathrm{CH}_{3} \mathrm{CH}_{2} \mathrm{O}\right) \mathrm{Si}\{\mathrm{OH})_{2}^{+}$ \\
97 & $\left.\mathrm{Si}_{(\mathrm{OH}}\right)_{4} \mathrm{H}^{+}$ \\
91 & $\left(\mathrm{CH}_{3} \mathrm{CH}_{2} \mathrm{O}\right) \mathrm{Si}(\mathrm{OH}) \mathrm{H}^{+}$ \\
79 & $\mathrm{Si}(\mathrm{OH})_{3}^{+}$ \\
63 & $\left.\mathrm{Si}^{+} \mathrm{OH}\right)_{2} \mathrm{H}^{+}$ \\
29 & $\left(\mathrm{CH}_{2}=\mathrm{CH}_{2}\right) \mathrm{H}^{+}$ \\
\hline
\end{tabular}

transition state onto a formally unsaturated group and concomitant or subsequent cleavage of the $\beta$ bond.

2. The origin of the product from the proposed precursor must be proven by a related metastable ion transition or unequivocal selection in a tandem mass spectrometry experiment.

3. The specificity of the hydrogen transfer must be experimentally verified.

Only a few cases are known where even-electron ions decay by a true McLafferty rearrangement. However, the initial interpretation of the spectra gave evidence that the TEOS/TPOS fragmentation might be another example of this mechanism.

From Scheme I it can be shown that a McLafferty rearrangement is possible, with the presence of a $\gamma$ hydrogen and the cleavage of the $\beta$-bond, therefore, the first criterion is met. In order to confirm whether the second criterion was true, MS/MS and double collision cell MS/MS experiments were performed. The MS/MS (daughter ion) experiments provided the structural information on the fragments resulting from the $[\mathrm{M}+\mathrm{H}]^{+}$parent ion. The double collision cell MS/MS experiments used each daughter ion as a parent ion and fragmented it further to produce grand-daughters, thus aiding in the elucidation of the structure of the daughter (fragment) ions. Figures 3

Table 3. Proposed structures of the daughter ions from $\operatorname{TPOS}[\mathrm{M}+\mathrm{H}]^{+}$

\begin{tabular}{ll}
\hline$m / z$ & \multicolumn{1}{c}{ Structure } \\
\hline \hline 265 & $\left.\mathrm{SilOCH}_{2} \mathrm{CH}_{2} \mathrm{CH}_{3}\right)_{4} \mathrm{H}^{+}$ \\
223 & $\left(\mathrm{CH}_{3} \mathrm{CH}_{2} \mathrm{CH}_{2} \mathrm{O}\right)_{3} \mathrm{SiOH} \mathrm{H} \mathrm{H}^{+}$ \\
181 & $\left.\left(\mathrm{CH}_{3} \mathrm{CH}_{2} \mathrm{CH}_{2} \mathrm{O}\right)_{2} \mathrm{SilOH}\right)_{2} \mathrm{H}^{+}$ \\
139 & $\left(\mathrm{CH}_{3} \mathrm{CH}_{2} \mathrm{CH}_{2} \mathrm{O}\right) \mathrm{Si}(\mathrm{OH})_{3} \mathrm{H}^{+}$ \\
97 & $\mathrm{SilOH}_{4} \mathrm{H}^{+}$ \\
79 & $\mathrm{SilOH}\}_{3}^{+}$ \\
43 & $\left(\mathrm{CH}_{3} \mathrm{CH}=\mathrm{CH}_{2}\right) \mathrm{H}^{+}$ \\
\hline
\end{tabular}

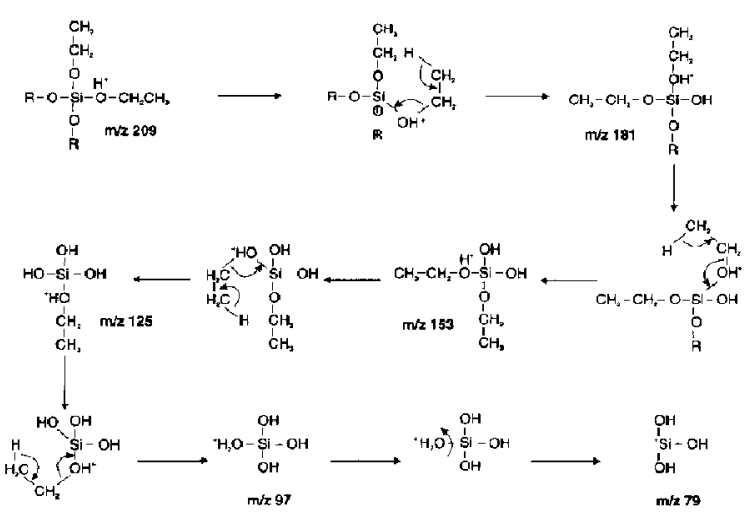

Scheme I. Proposed fragmentation of TEOS by McLafferty rearrangement.

and 4 show the results of the double collision cell experiments for TEOS and TPOS, respectively. In each figure the "family tree" illustrates the parentage of the ions. It is evident that from each rearrangement daughter ion, another daughter/grand-daughter ion is evolved by way of a successive mechanism. For example, the daughter ion of $m / z 181$ in TEOS is the result of a single rearrangement with a single ethylene loss and the grand-daughter spectrum of the daughter ion of $m / z 181$ shows fragments of $m / z 153,125$, and 97 . Each of these fragments is also the result of successive ethylene losses from the original parent ion. The grand-daughter MS/MS spectra of the other suspected rearrangement daughter ions ( $m / 2153$ and 125) each showed additional successive ethylene losses.

Using a collision energy $\left(\mathrm{E}_{\mathrm{lab}}\right)$ of $30 \mathrm{eV}$, the fragmentalion of both TEOS and TPOS was investigated as a function of increasing target thickness to further determine the origin of proposed rearrangement precursor ions. Figures 5 and 6 show the variation of

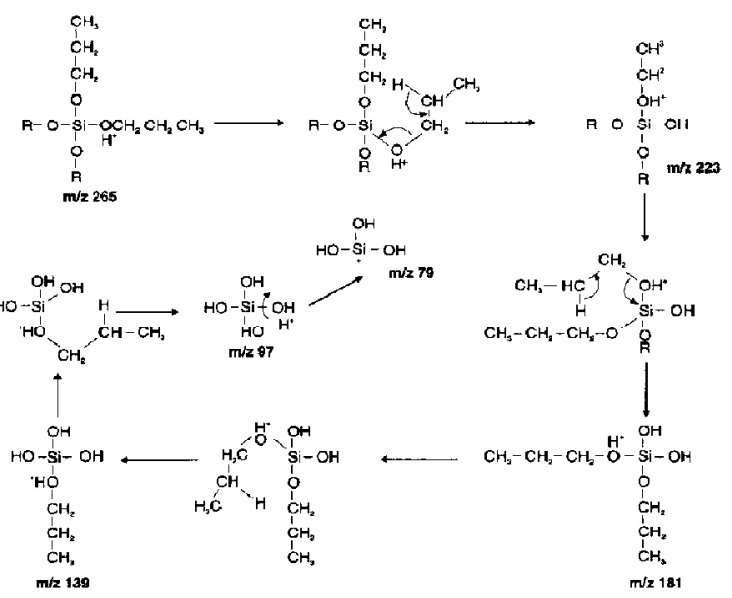

Scheme II. Proposed fragmentation of TPOS by McLafferty rearrangement, 


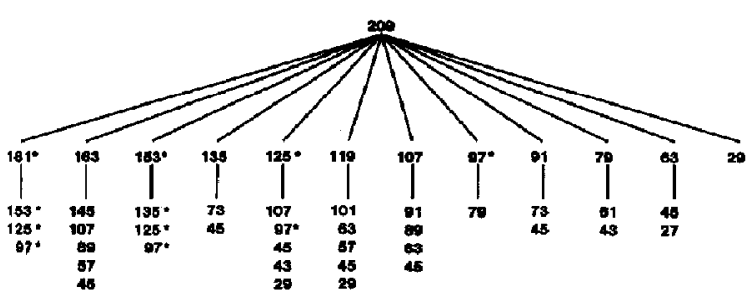

Figure 3. Daughter and grand-daughter ions produced from the MS/MS and MS/MS double collision cell experiments using TEOS. An asterisk indicates that the ions are derived via a rearrangement mechanism.

daughter ion intensity as a function of collision target gas. As the target thickness is increased from having the collision gas off to approximately $2.4 \times 10^{14}$ molecules $/ \mathrm{cm}^{2}$ the abundance of all fragment ions increased. As the target thickness was increased further the number of collisions that the molecule underwent increased to the point where multiple sequential rearrangements reactions occurred. In TEOS the intensity of ions with $m / z 181,163,153$, and 125 began to substantially decrease (see Figure $5 a$ ) with the intensity of ions of $m / z 97,79$, and 29 showing an increase in intensity (see Figure 5b). (Recall that the ions with $m / z 181,153$, and 125 represent successive losses of one, two, and three ethylene groups.) The increasing and finally leveling off of signal from $m / z 97,79$, and 29 while all other ions decrease in intensily indicales that these ions are effective terminations of fragmentation sequences.

The same fragmentation patterns are evident in the TPOS MS/MS daughter ion and double collision cell MS/MS experiments, as in the TEOS experiments. This indicates that the TPOS parent ion is undergoing fragmentation by the same mechanism. The intensity of the peaks corresponding to $m / z \quad 223,181$, and 139 (representing the first three successive propylene losses) all increase (see Figure 6a) up to a target gas thickness of approximately $2 \times 10^{14}$ molecules $/ \mathrm{cm}^{2}$. Then as the target gas thickness increases the effective end termination fragments $(m / z 97,79$, and 43$)$ increase in intensity at the expense of the earlier rearrangement ions (see Figure 6b). Therefore, the results of these double collision cell MS/MS experiments (Fig-

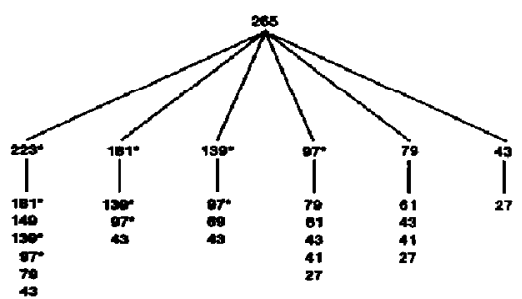

Figure 4. Daughter and grand-daughter ions produced from the MS/MS and MS/MS double collision cell experiments using TPOS. An asterisk indicates the ions are derived via a rearrangement mechanism.
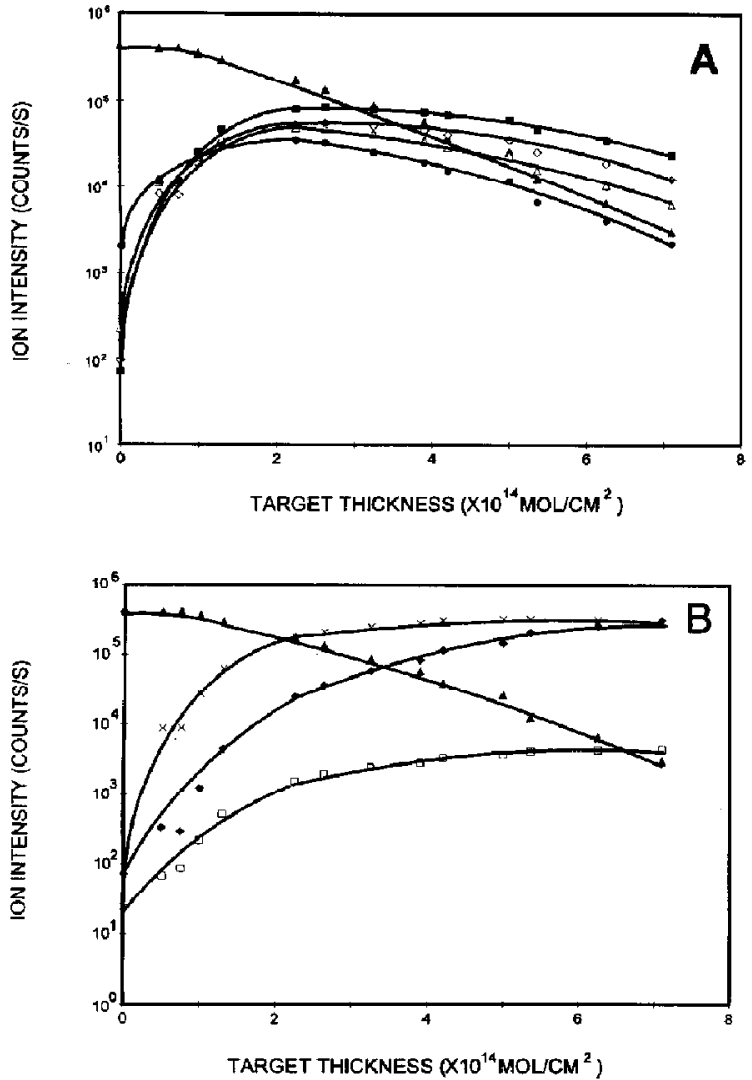

Figure 5. (a) The variation of ion abundance with target thickness for the daughter ions of $[\mathrm{M}+\mathrm{H}]^{+}$from tetraethyl ortho silicate. Collision energy as $30 \mathrm{eV}$. (. ) $m / 2209,(\infty) \mathrm{m} / \mathrm{z} 181$, ( $)$ $m / z$ 163, ( $\Delta) m / z$ 153, (a) $m / z$ 125. (b) The variation of ion abundance with target thickness for the daughter ions of $[\mathrm{M}+$ $\mathrm{H}^{+}$from tetraethyl ortho silicate. Collision energy as $30 \mathrm{eV}$. (A) $m / z$ 209, (X) $m / z 97$, (৬) $m / z 79$, (口) $m / z 29$.

ure 4) illustrate that the daughter ions are fragmenting by the same process as the parent ions.

This evidence fulfills the second criterion for the McLafferty rearrangement suggested by Zollinger and Seibl. The family trees and the fragment ion intensity variation with target thickness indicate that each successive rearrangement ion has a precursor of a daughter ion from the original $[\mathrm{M}+\mathrm{H}]^{+}$parent ion.

In order to check the validity of the third criterion, namely the specificity of the hydrogen transfer, an isotopic label must be placed in the compound and the MS/MS daughter ion spectrum obtained in order to characterize the structure of the daughter ions. Deuterium labeled TEOS and TPOS were synthesized with the deuterium atoms located in the $\gamma$-position yielding $\mathrm{D}_{12}$-TEOS, $\left(\mathrm{CD}_{3} \mathrm{CH}_{2} \mathrm{O}\right)_{4} \mathrm{Si}$, and $\mathrm{D}_{8}$-TPOS, $\left(\mathrm{CH}_{3} \mathrm{CD}_{2} \mathrm{CH}_{2} \mathrm{O}\right)_{4} \mathrm{Si}$. Once synthesized, MS/MS daughter ion spectra of the $[\mathrm{M}+\mathrm{H}]^{+}$ions were obtained. Figures 7 and 8 show the MS/MS daughter ion spectra of $\mathrm{D}_{12}$-TEOS, $(\mathrm{m} / \mathrm{z} 221)$, and $\mathrm{D}_{8}$-TPOS $(\mathrm{m} / \mathrm{z}$ 273), respectively. 

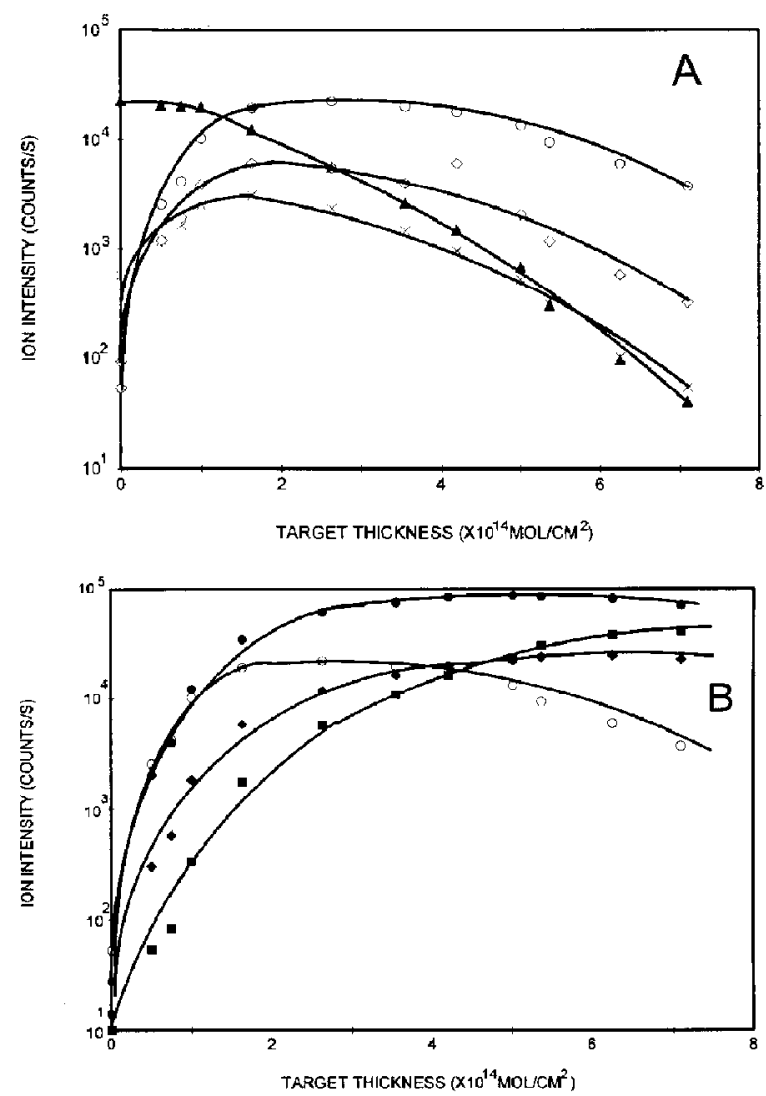

Figure 6. (a) The variation of ion abundance with target thickness for the daughter ions of $\left[\mathrm{M}+\mathrm{H}^{+}\right.$from tetrapropyl ortho silicate. Collision energy as $30 \mathrm{ev}$. ( 4$) \mathrm{m} / \mathrm{z} 265,(\mathrm{X}) \mathrm{m} / \mathrm{z} 223,(\varphi)$ $m / z 181,(0) m / z 139$. (b) The variation of ion abundance with target thickness for the daughter ions of $[\mathrm{M}+\mathrm{H}]^{+}$from tetrapropyl ortho silicate. Collision energy as $30 \mathrm{ev},(0) \mathrm{m} / z 139$, (৬) $m / z 43,(\square) m / z 79,(\bullet) m / z 97$.

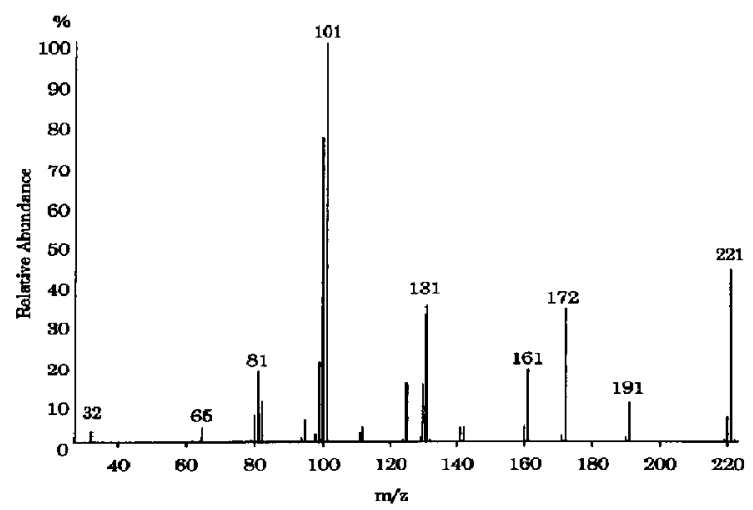

Figure 7. APCI tandem mass daughter ion spectrum of $[\mathrm{M}+\mathrm{H}]^{+}, m / z 221$, from deuterated tetraethyl ortho silicate, $\left(\mathrm{CD}_{3} \mathrm{CH}_{2} \mathrm{O}\right)_{4} \mathrm{Si}$.

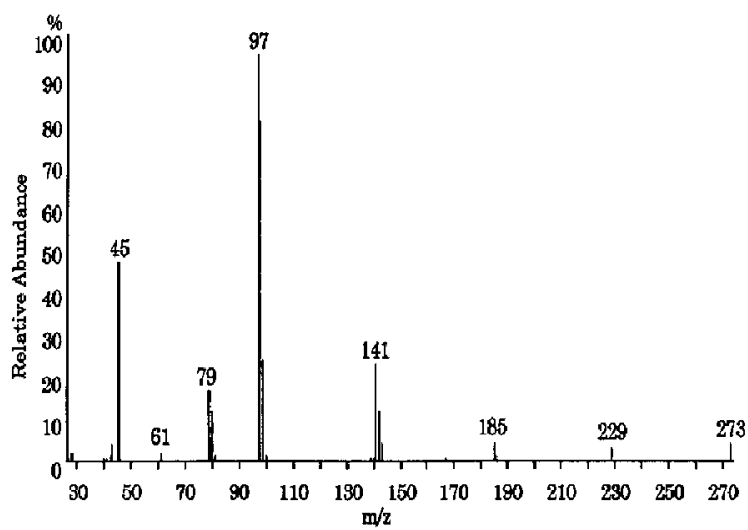

Figure 8. APCl tandem mass daughter ion spectrum of $[\mathrm{M}+\mathrm{H}]^{+}, m / z 273$, from deuterated tetrapropyl ortho silicate, $\left(\mathrm{CH}_{3} \mathrm{CD}_{2} \mathrm{CH}_{2} \mathrm{O}\right)_{4} \mathrm{Si}$.

The $D_{12}$-TEOS spectra does show successive losses of $m / z \quad 30\left(\mathrm{CD}_{2}=\mathrm{CH}_{2}\right)$ illustrating that the $\gamma$ hydrogen is involved in the rearrangement. But, in addition to the base peak at $m / z 101\left(\mathrm{Si}(\mathrm{OD})_{4} \mathrm{H}^{+}\right)$, peaks surrounding the base peak are also present $(\mathrm{m} / \mathrm{z}$ 100, 99, and 98), indicating a mix of hydrogens and deuteriums in the end terminal rearrangement. This shows that the rearrangement mechanism is not specific to the original $\gamma$-hydrogen or that scrambling of the deuterium atoms within the alkane chain occurred before the beta bond cleavage. Upon close examination of the other rearrangement peaks in the daughter spectra $(m / z 191,161,131)$ small amounts of nondeuterated rearrangement peaks are present for these ions. In the first ethylene loss, the nondeuterated peak $(\mathrm{m} / \mathrm{z}$ 190) accounts for $11 \%$ of this fragmentation. In the second ethylene loss, the nondeuterated peaks $(\mathrm{m} / \mathrm{z}$ $160,159)$ account for $16 \%$ of this fragmentation. In the third ethylene loss, the nondeuterated peaks $(\mathrm{m} / z 130$, 129,128 ) account for $28 \%$ of this fragmentation. And in the find ethylene loss the nondeuleraled peaks $(m / z$ $100,99,98,97$ ) account for $50 \%$ of the fragmentation. The mix of hydrogens and deuteriums in each successive rearrangement indicate that $\gamma$-hydroger/ deuterium is not solely involved in this fragmentation mechanism.

The $\mathrm{D}_{8}$-TPOS daughter ion spectrum also shows evidence of successive propylene losses but not of the proper masses corresponding to a transfer of the original $\gamma$-deuterium. The base peak in the spectra is $m / z$ $97\left(\mathrm{Si}(\mathrm{OH})_{4} \mathrm{H}^{+}\right)$indicating no deuteriums in this daughter ion. There are several peaks that surround the base peak $(m / z 98,99$, and 100$)$, indicating varying degrees of deuteration. Examination of each step in the successive rearrangements indicates that the $\gamma$ deuterium is not uniquely transferred in each rearrangement. In the first propylene loss, $100 \%$ of the rearrangement occurs without a deuterium. The second propylene loss occurs with a deuterium present in 
only $40 \%$ of the fragmentation. In the third propylene loss, only $46 \%$ of the fragmentation have a deuterium present in the molecule and the final propylene loss, only $54 \%$ of the total have deuterium (1-4) present. As in the $D_{12}$-TEOS case, the mix of hydrogens and deuteriums in each of the successive rearrangements indicates the $\gamma$-hydrogen/deuterium is not the only species being transferred during the fragmentation.

These results indicate that the third criterion suggested by Zollinger and Seibl has not been met to substantiate the claim that the rearrangements in the MS/MS daughter ion spectra of TEOS and TPOS are due to simple McLafferty rearrangements involving the original $\gamma$-hydrogen.

The other possible reaction mechanism considered was the formation of ion-neutral complexes. Harnish and Holmes [18] described gas phase ion-neutral/ ion-molecule/ion-radical/ion-dipole complexes as "species in which an ion and a neutral are bound chiefly by electrostatic forces." Recent studies of gas phase ion chemistry show the importance of these ion-neutral complexes in reaction mechanisms in both electron ionization spectra and chemical ionization spectra using a variety of reagent gases $[3,4,12-20]$. Cairns et al. also showed that successive ion-dipole complexes are responsible for the CI fragmentation pattern of propoxur, a carbamate pesticide [21]. The fragmentation of TEOS and TPOS may be further examples of even electron fragmentation by way of multiple and successive ion-dipole complexes.

As an extrapolation from Harnish and Holmes' sludy [18] of ion-neutral complexes formed from ethyl phenyl ethers, and Morton's study [22] of alkyl phenyl ethers, we propose that TEOS and TPOS rearrange by ion-neutral complex formation as well. Scheme III illustrates the suggested mechanism for the fragmentation of TEOS using ion-neutral complexes.

Evidence that ion-neutral complexes are involved in the TEOS fragmentation can be drawn from the calculated (assuming complete randomization) versus observed hydrogen interchange data shown in Tables 4

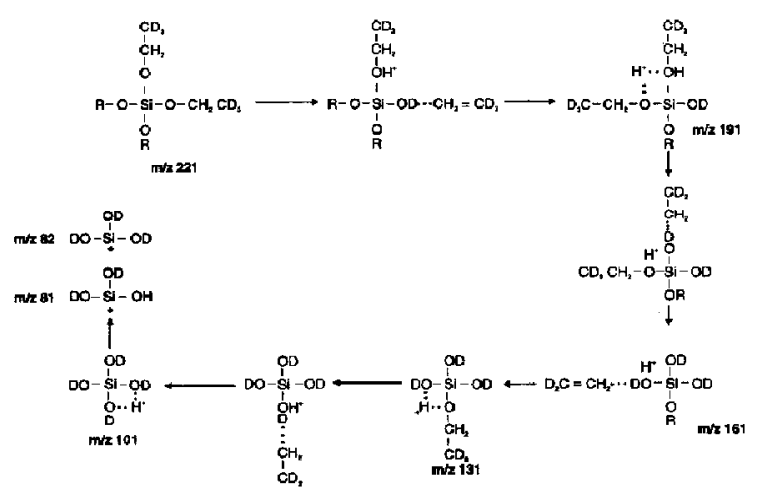

Scheme III. Proposed fragmentation of TEOS by way of ionneutral complexes.
Table 4. Observed versus calculated distributions of hydrogen and deuterium in TEOS daughter ion spectra rearrangements

\begin{tabular}{rccc}
\hline $\boldsymbol{m} / \boldsymbol{z}$ & $\begin{array}{c}\text { D } \boldsymbol{A H} \\
\text { Distribution }\end{array}$ & $\begin{array}{c}\text { Observed } \\
(\%)\end{array}$ & $\begin{array}{c}\text { Calculated } \\
(\%)\end{array}$ \\
\hline \hline 191 & D & 89 & 60 \\
190 & H & 11 & 40 \\
161 & DD & 82 & 36 \\
160 & DH & 16 & 48 \\
159 & HH & 2 & 16 \\
& & & \\
131 & DDD & 67 & 21 \\
130 & DDH & 28 & 43 \\
129 & DHH & 23 & 28 \\
128 & HHH & 0.4 & 6 \\
& & & \\
101 & DDDD & 50 & 13 \\
100 & DDDH & 38 & 34 \\
99 & DDHH & 10 & 35 \\
98 & DHHH & 1 & 15 \\
97 & HHHH & 0.1 & 3 \\
\hline
\end{tabular}

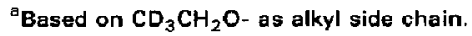

and 5. (The calculated distributions were not corrected for carbon-13 contributions because the carbon-12 species was always selected by the first mass spectrometer in the MS/MS experiments.) Because the hydrogen/deuterium distributions do not correspond to a specific transfer of the $\gamma$-deuterium nor do they correspond to a random distribution, isomerization in the alkyl side chains must be occurring. This side chain isomerization has been attributed to the formation of

Table 5. Observed versus calculated distributions of hydrogen and deuterium in TPOS daughter ion spectra rearrangements

\begin{tabular}{rccc}
\hline$m / z$ & $\begin{array}{c}\text { D } / H \\
\text { Distribution }\end{array}$ & $\begin{array}{c}\text { Observed } \\
\text { (\%) }\end{array}$ & $\begin{array}{c}\text { Calculated } \\
(\%)\end{array}$ \\
\hline \hline 230 & D & 0 & 25 \\
229 & H & 100 & 75 \\
187 & DD & 13 & 6 \\
186 & DH & 27 & 38 \\
185 & HH & 59 & 56 \\
& & & \\
144 & DDD & 0 & 2 \\
143 & DDH & 8 & 14 \\
142 & DHH & 38 & 42 \\
141 & HHH & 54 & 42 \\
& & & \\
101 & DDDD & 0 & 0.3 \\
100 & DDDH & 1 & 5 \\
99 & DDHH & 13 & 21 \\
98 & DHHH & 40 & 42 \\
97 & HHHH & 45 & 32 \\
\hline
\end{tabular}

aesed on $\mathrm{CH}_{3} \mathrm{CD}_{2} \mathrm{CH}_{2} \mathrm{O}$ - as alkyl side chain. 
ion-neutral complexes [20]. In addition to side chain isomerization, the alkyl side chain (neutral part of the ion-neutral complex) may undergo an "end-over nip" [23] (where the neutral part of the complex rotates $180^{\circ}$ ), thus in the case of $D_{12}$-TEOS, placing the $C D_{3}$ deuteriums closer to the ether oxygen and the transfer of the deuteriums becomes preferential. This end-over flip may explain the observed high percentage of deuterated daughter ions in the $D_{12}$-TEOS MS/MS spectra (by placing the deuteriums in closer to the ionic part of the complex), yet allow for the hydrogen transfer during the ethylene losses as well if the chain flips an even number of times.

Scheme IV illustrates the suggested mechanism for the fragmentation of TPOS using ion-neutral complexes and Table 5 shows the observed versus calculated hydrogen/deuterium (H/D) distributions. Similar to the $\mathrm{D}_{12}$-TEOS data, the observed versus calculated (based on random statistics) ratios of hydrogen to deuterium species in the daughter ions suggests that ion neutral complexes are involved in the fragmentation mechanism. In the $D_{8}$-TPOS spectrum the $H / D$ ratios strongly favor the hydrogen transfer in the rearrangement, unlike in $D_{12}$-TEOS where the deuterium transfer was dominant. In order for the hydrogens to be preferentially transferred, an isomerization of the n-propyl side chain must take place. N-propyl chain isomerization to an isopropyl or cyclopropyl complex before fragmentation was previously demonstrated [13, 18, 24-26]. The isopropyl isomer is the lowest energy configuration. Other studies also provide evidence that small chain hydrocarbons undergo unimolecular isomerizations in the gas phase $[24,25,27,28]$ and under solvolytic conditions in the condensed phase [29, 30] (indicating that the gas phase structures seen in this study may mimic the solution phase structures observed for $\mathrm{SiO}_{2}$ ). Audier et al. [5] showed that the

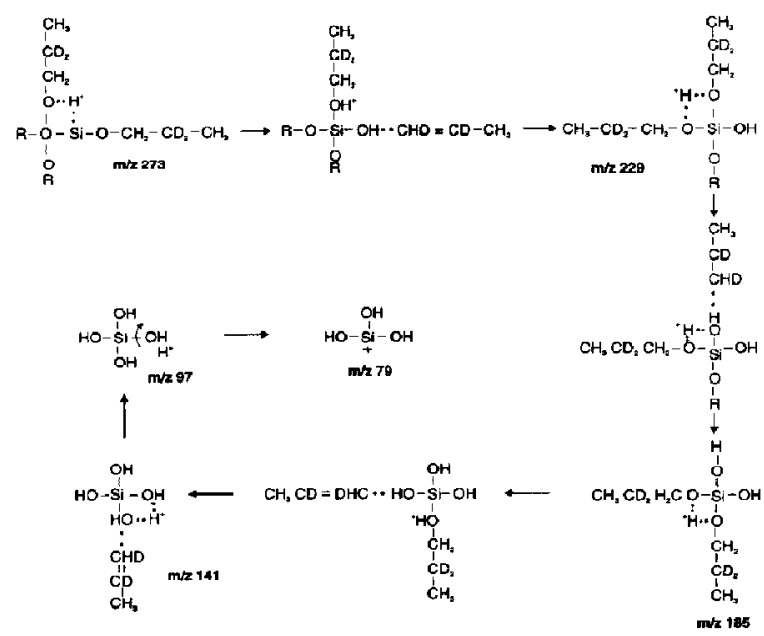

Scheme IV. Proposed fragmentation of TPOS by way of ionneutral complexes. isomerization of the n-propyl to the iso-propyl takes place before metastable decomposition. McAdoo et al. [31] showed that the hydrogen/deuterium transfer is preferentially from the $C_{1}$ and $C_{3}$ for eliminations of propene from n-propyl ions (rearrangement to the isopropyl isomer making $C_{1}$ and $C_{3}$ equivalent). The isomerization of the n-propyl side chain to the isopropyl configuration occurs during the lifetime of an ion-neutral complex before fragmentation of the ion. In each of the four successive rearrangements resulting in propylene losses from $\mathrm{D}_{8}$-TPOS, the ion which represents the transfer of a hydrogen is favored over the transfer of the deuterium $(m / z 229,185,141,97)$. Accordingly, for the base peak of the $D_{8}$-TPOS spectrum, $m / z$ 97, no deuteriums were transferred during any of the four rearrangements. (Peaks at masses $m / z$ 98 and 99 are also present and show that in $50 \%$ of the four ethylene loss rearrangement only 1-2 deuteriums were transferred during the rearrangements).

Since the $H / D$ ratios do not favor a transfer of the $\gamma$-hydrogen nor represent a random distribution, and others have observed the isomerization of propyl side chains, we suggest that the fragmentation of the TPOS parent ions also proceeds via ion-neutral complexes.

Although both the TEOS and TPOS are fragmenting via ion-neutral complexes, the atoms transferred from the neutral part of the complex to the ionic part of the complex are different. In the $\mathrm{D}_{8}$-TPOS spectrum hydrogen transfers are dominant and in the $D_{12}$-TFOS spectrum the deuteriums are the dominant species transferred. The deuterium transfer predominates in the $D_{12}$-TEOS spectrum due to the statistical dominance of deuteriums in the alkyl side chains (three out of five positions occupied by a deuterium). The deuterium transfer is also preferential in the end-flipping of the side chain because the deuterium is placed closer to the ionic part of the complex.

In $\mathrm{D}_{8}$-TPOS the statistics favor the hydrogen transfer over the deuterium transfer (two out of seven positions occupied by a deuterium) during the rearrangement. In addition, if the n-propyl side chain should end-flip, a hydrogen would preferentially transfer as both ends of the n-propyl chain are occupied by hydrogens. If the n-propyl side chain isomerized to the isopropyl configuration, then a deuterium could transfer to the ion via the complex. In the event that fragmentation proceeds via an ion-neutral complex and McLafferty rearrangements in tandem, then the hydrogens that were originally on the $C-1$ and $C-3$ positions isomerize to the $\gamma$-position and will be preferentially transferred to the ion via the McLafferty rearrangement. In summary, the side chains of the $\mathrm{D}_{8}$-TPOS parent ion may undergo an end-flip as well as isomerization into the isopropyl configuration. In addition, the greater number of hydrogens in the propyl side chain also favors the transfer of a hydrogen over a deuterium which accounts for the preferential transfer of the hydrogen instead of the deuterium as in $\mathrm{D}_{12}$-TEOS. 
Experiments using $\mathrm{D}_{2} \mathrm{O}$ as the reagent gas were also performed with both TEOS and TPOS to further determine the composition of their respective daughter ions and fragmentation mechanisms. Figures 9 and 10 show the daughter ion spectra of TEOS and TPOS using $\mathrm{D}_{2} \mathrm{O}$ as the reagent gas. As in the $\mathrm{H}_{2} \mathrm{O}$ spectra the site of protonation is one of the ether oxygens as they are the most basic site on the molecules. The TEOS spectrum shows that there is no interchange between the ionizing deuterium and the hydrogens on the alkyl side chains as each of the daughter ions from the $\mathrm{D}_{2} \mathrm{O}$ experiment are only one mass unit different than its $\mathrm{H}_{2} \mathrm{O}$ counterpart. The ionizing deuterium is present on the ion throughout the sequential losses of ethylenes $(m / z 182,154,126$, and 98). Similar results were obtained by McMahon and Harrison [20] in a study of protonated ethyl esters where no exchange between the ionizing deuterium and the alkyl side chain took place when the fragmentation took place via ionneutral complexes.

However, when TPOS is ionized with $\mathrm{D}_{2} \mathrm{O}$, some interchange of the deuterium with the hydrogens on the alkyl side chain is observed. (This is why the statistics in Table 5 were calculated using eight total hydrogens or deuteriums that can be involved in the side chain scrambling. Figure 10 shows that there is a mix of $\mathbf{H}$ and $\mathrm{D}$ transfer for all of the ethylene losses $(m / z 223 / 224, m / z 181 / 182, m / z 139 / 140, m / z$ 97/98, and $m / z 13 / 11)$. Interchanges of this type have been observed in protonated ethanol [32] and protonated methyl isopropyl ether [33] and have been rationalized [34] using ion-neutral complexes as intermediates in the fragmentation of several protonated species [18]. Morton [23] showed that as the size of the alkyl side chain increases it becomes more polarizable and the corresponding neutral fragment in the ion-neutral complex should be more strongly attracted to the ion. If the intermolecular distance between the ionic and neutral part of the ion-neutral complex is small, then the ionizing hydrogen/deuterium may migrate to the

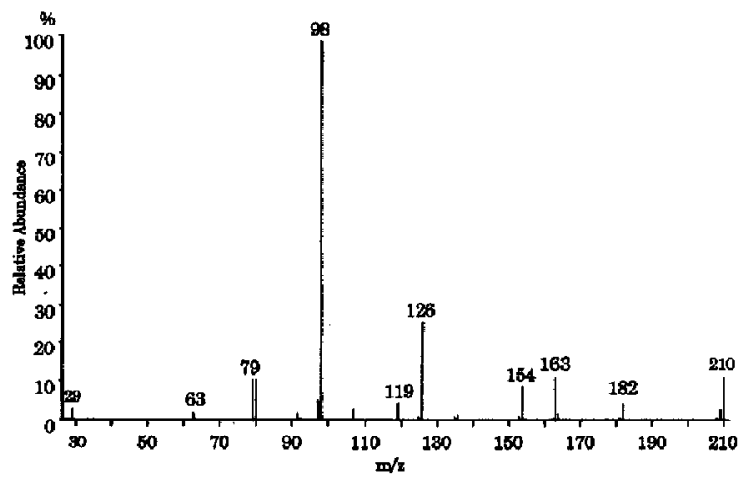

Figure 9. APCI tandem mass daughter ion spectrum of $[\mathrm{M}+\mathrm{H}]^{+}, m / 2210$, from tetraethyl ortho silicate using $\mathrm{D}_{2} \mathrm{O}$ as the reagent gas.

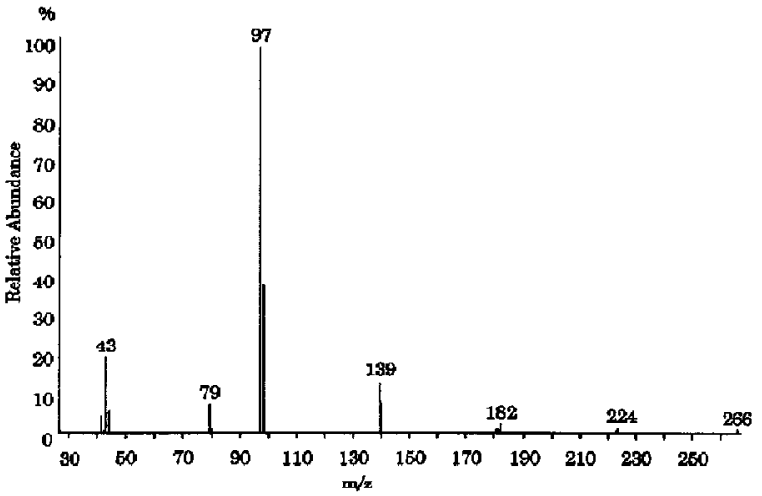

Figure 10. APCI tandem mass daughter ion spectrum of $[\mathrm{M}+\mathrm{H}]^{+}, m / z 266$, from tetrapropyl ortho silicate using $\mathrm{D}_{2} \mathrm{O}$ as the reagent gas.

alkyl chain and be intermixed with the original hydrogens/deuteriums present in the side chain as the ionneutral complex is formed. In the case of TEOS the side chain may not be polarized to the extent that the hydrogen/deuterium can overcome the intermolecular distances of the complex to transfer the hydrogen/ deuterium to the ethyl chain. The propyl side chain in TPOS must be polarized enough to allow for the ionizing deuterium to transfer to the alkyl side chain and have it mix with the original hydrogens/deuteriums since both a deuterated and a nondeuterated daughter ion are present in the MS/MS spectra. Morton [23] also showed that the hydrogen scrambling in the alkyl side chain is independent of the ionizing hydrogen/deuterium scrambling.

All of this evidence suggests that TEOS and TPOS undergo fragmentation via ion-neutral complexes and nut by a simple McLafferty rearrangement. The details involved in the ion-neutral complex fragmentation can only be completely verified by a large number of isotope labeling experiments followed by mass analysis. However, the mechanisms proposed herein fit well with the observed data.

A variation of the ion-neutral complex mechanism may have some credence in the elucidation of the fragmentation mechanism of TEOS and TPOS. This variation combines the formation of an ion-neutral complex (allowing for the side chain isomerization) followed by the fragmentation via the McLafferty rearrangement. This phenomena would yield the same observed data as seen in the MS/MS daughter ion spectra obtained in this study. McAdoo and Morton [19] and McAdoo [31] have shown that fragmentation mechanisms involving ion-neutral complexes can occur in conjunction with other mechanisms to explain the overall fragmentation scheme of a molecule. But at this time it may be impossible to devise experiments to differentiate between the fragmentation by ion-neutral complexes and the combina- 
tion of ion-neutral complexes and McLafferty type rearrangements.

\section{Conclusions}

Taking into consideration all of the data gathered in this study, it appears that the protonated TEOS and TPOS molecules undergo fragmentation via a rearrangement reaction that is not a true McLafferty rearrangement with hydrogen specificity to the original $\gamma$-hydrogen. These molecules failed to meet all of the criteria suggested by Zollinger and Seibl in establishing proof of a true McLafferty rearrangement. The evidence presented in this study indicates that the fragmentation proceeds via a series of ion-neutral complexes.

Other types of ethers and esters (e.g., phosphonates) [35] also have neutral fragment losses that superficially might be assigned to a McLafferty type rearrangement under APCI and low energy CID experiments. It is quite possible that those reactions may also be explained more correctly by an ion-neutral complex route of decomposition. These inn-molecule reactions of TEOS and TPOS with hydronium jons under APCI conditions yield species similar to those found in the solution phase reactions of TEOS with water in the formation of silica gels under acidic conditions [1, 2]. (Specifically ions with $m / z 181,153$, and 97.) Since parallels exist between gas phase ion chemistry and solution phase ion chemistry, it is likely that the ionneutral complexes may contribute to the hydrolysis of TEOS and TPOS in the solution phase as well.

\section{References}

1. Campostrini, R.; Cauturan, G.; Pelli, B.; Traldi, P. J. Non-Cryst. Solids 1989, 108, 143-149.

2. Campostrini, R.; Carturan, G.; Soraru, G.; Traldi, P. I. NonCryst. Solids 1989, 108, 315-322.

3. Kondrat, R. W.; Morton, T. H. J. Org. Chem. 1991, 56, 952-957.

4. Kondrat, R. W.; Morton, T. H. Org. Mass Spectrom. 1991, 26, 410-415.

5. Audier, H. E.; Morton, T. H. Proceedings of the 41st Annual ASMS Conference on Mass Spectrometry and Allied Topics; San Francisco, CA, 1993.

6. Dawson, P. H.; French, J. B.; Buckley, J. A.; Douglas, D. J.; Simmons, D. Org. Mass Spectrom. 1982, 17, 205-211.
7. Dawson, P. H.; French, J. B.; Buckley, J. A.; Douglas, D. J.; Simmons, D. Org. Mass Spectrom. 1982, 17, 211-218.

8. Good, A.; Durden, D.; Kebarle, P. J. J. Chem. Phys. 1970, 52, 222-228.

9. Sunner, J.; Nicol, G.; Kebarle, P. J. Anal Chem. 1988, 60, $1300-1306$.

10. Dearing, A. W.; Reid, E. E. J. Amer. Chem. Soc. 1928, 50 , 3058-3062.

11. Zollinger, M.; Seibl, J. Org. Mass Spectron. 1985, 11, 649-661.

12. Hammerum, S. Mass Spectrom. Rev. 1988, 7, 123-202.

13. Chronister, E. L.; Morton, T. H. I. Amer, Chem. Soc. 1990, 112, 133-139.

14. Longevialle, P. Org. Mass Spectrom. 1985, 20, 644-645.

15. Morton, T. H. Org, Mass Spectrom. 1991, 26, 18-23.

16. McAdoo, D. J. Mass Spectrom. Rev. 1988, 7, 363-393.

17. Morton, 'I'. H. 'Tetrahedron 1982, 38, 3195-3243.

18. Harnish, D.; Holmes, J. L. I. Am. Chem. Soc. 1991, 113, 9729-9734.

19. McAdoo, D. J.; Mortun, T. H. Acc. Chem. Res. 1993, 26, 295-302.

20. McMahon, A. W.; Harrison, A. G. Can. J. Chem. 1988, 66, 2403-2409.

21. Cairns, T.; Siegmund, E. G.; Stamp. J. J. Org. Mass Spectrom. 1986, 21, 161-164.

22. Morton, T. H. I. Am Chem. Soc. 1980, 102, 1596-1602.

23. Morton, T. H. Org. Mass Spectrom. 1992, 27, 353-368.

24. Benoit, F. M.; Harrison, A. G. Org. Mass Spectrom. 1976, 11, 599-508.

25. Koch, W.; von Rague Schleyer, P.; Buzek, P.; Liu, B. Croatia Chemica Acta 1992, 65, 655-672.

26. Saunders, M.; Hewett, A. P.; Kronja, O. Croatia Chemica Acta 1992, 65, 673-678.

27. Stapleton, B. J.; Bowen, R. J.; Williams, D. H. Tetrahedron 1978, $34,259-265$.

28. Bowen, R. D.; Stapleton, B. J.; Williams, D. H. Org. Mass Spectrom. 1978, 31, 2431-2438.

29. Olah, G. A.; Olah, H. A. In Carbonium Ions, Vol II; Olah, G. A.; Schleyer, P. V. R., Eds. Wiley-Interscience: New York, 1974, Chapter 17.

30. Hudson, C. E.; Lin, T.; McAdoo, D. J. Org. Mass Spectrom. 1987, 22, 311-315.

31. McAdoo, D. J.; Hudson, C. E.; Skyiepal, M.; Broido, E.; Griffin, L. L. J. Am. Chem. Soc. 1987, 109, 7648-7653.

32. Benoit, F. M.; Harrison, A. G. J. Am. Chem. Soc. 1977, 99, 3980-3984.

33. Terlouw, J. K.; Wieske, T.; Schwartz, H.; Holmes, J. L. Org. Mass Spectrom. 1986, 21, 665-671.

34. Harrison, A. G. Org. Mass Spectrom. 1987, 22, 216-228.

35. Snyder, A. P.; Harden, C. S. Org. Mass Spectrom. 1990, 25, 301-308. 